\title{
Development of Paternalistic Strategy of Industrial Growth with Regard to Institutional Traps (Qwerty- Effects)
}

\author{
Bagautdinova N. ${ }^{a}$ \\ Sarkin A. ${ }^{b}$ \\ Khadiullina G. \\ Averyanov B.c1 \\ Arzhantseva N.d \\ a bcd Kazan Federal University, Kazan, 420008, Russia \\ 1Email address: verkbund@gmail.com
}

\section{Doi:10.5901/mjss.2014.v5n12p49}

\section{Abstract}

The article provides the theoretic-methodical approach to the content of paternalistic strategies of development of industry. The given approach takes the principles of behavioural economy as the basis and explains the necessity of methods of state regulation by the existence of institutional traps (QWERTY effects) and cognitive and behavioural anomalies corrected as a result of state implantation of the normative standard into the structure of subjective preferences of economic agents. The article provides rationalization for the necessity of application of measures of the direct influence limiting possibilities of an individual choice present at a high risk level of irrational behavior, and the measures of indirect influence correcting an individual choice of short-term benefit, interfaced with high expenses in the long-term period.

Keywords: "New" paternalism, paternalistic state, paternalistic strategy of industrial development, QWERTY effects, state regulation of economy, normative standards, behavioural anomalies.

\section{Introduction}

Consequences of destructive measures taken as regards to institutes of state regulation have long-term character and reveal themselves in post-crisis stagnation of the real sector of Russian economy. According to official data, in the period from 2009 to 2012 the growth rates of labor productivity as the main indicator of economic efficiency of production were twice lower than the pre-crisis indicators. Negative tendencies are observed in the industrial sphere the volume growth of which made 2,6\% in 2012 reaching the value of $8,2 \%$ in 2010. Decrease of the volume of external demand, lack of gains of investments into basic stock, increase in tax burden, high energy intensity, etc. - all this causes the negative tendencies of development of industrial production in 2013.

The category of paternalism is a part of the conceptual construct of different social sciences, among which there are philosophy (V.Gumbold, J.Dvorkin, I.Kant, R.Carter, J.Feinberg, S.Li), history (F.Aryes, E.Gibbon, J. le Goff, A.Gurevich, J.Dubie, T.Ermolenko, F.de Coulange, T.Mommsen, N.Silvansky, S.Solovyev, etc.), sociology (S.Aizenstadt, B.Arizi, E.Green, P.Kinston, N.Marantsidis, L.Mid, L.Ronniger, S.Chang, etc.).

At the same time in a number of researches devoted to economy, an attempt is made to consider paternalism as a special type of contract relations subject to evolutionary changes (M.Afanasyev, P.Romanova, R.Kapelyushnikov, etc.).

The conducted research showed $[9 ; 10 ; 11]$ that there are no complex researches of the features of Russian economy development which is defined by general economic laws and, at the same time, is characterized by a number of features caused by a set of objective and subjective factors. There has been an insufficient analysis conducted on the issues of influence of multistructurality of Russian economy on the state of factors of the external and internal environment of economic entities and the prospects of their development. All this predetermined the necessity of research of the paternalistic concept and opportunities of its application when developing measures of state regulation of economy. 


\section{Methodology}

The behavioural economy serves as the theoretical base of new paternalism which represents an integral concept and a certain stage of development of human civilization characterized by the state performing the function of formation and implantation of normative (estimating) standards of behavior into the system of preferences of economic agents. Unlike the welfare economy, the new paternalistic economy recognizing existence of shortcomings ("failures") of the market and the necessity of their regulation also recognizes the existence of the behavioural anomalies, following from irrationality of its agents. It expands the borders of the state intervention and provides the necessity of the replacement of methods of indirect regulation by the methods of the direct influence, presented by methods of institutional design.

In the conditions of turbulence of market economy the need of economic agents for the institutional design providing decrease in the level of information asymmetry is formed. However, strong institutes as the result of their planning and design can have self-supporting inefficient character which hinders the progressive development of economic and social indicators ("effect of blocking"). The technical-technological factors causing change of technological mode act as a necessary source of inefficient institutes, namely: post-industrial society characterized by the realization of product, administrative and technological innovations which defines high uncertainty and stochasticity of economy, and also risk increase as a quantitative index of this uncertainty. Along with technical-technological factors the existence of plurality of cognitive and behavioural anomalies acts as a necessary condition of nascence of QWERTY-effects [2].

The institutional projects realized with the violation of the principles of institutional planning, and the social capital treated as a set of explicit and implicit contracts (social interactions) act as sufficient conditions for nascence of inefficient institutes at the present stage of development of the society [4]. As a condition for maintaining a self-sustaining institute there may be considered the excess of the expenses on the inefficient norm cancellation over the expenses for its functioning, and also the excess of expenses on introduction of a new norm over the expenses on the resistance to it. It may be caused by the existence of the contract enforcement mechanism providing sanctions against the violators of the existing rule.

The above mentioned conditions provide long existence of inefficient institutes of the state regulation presented by the methods of a re-location of resources to increase the level of efficiency of their use and also by the instruments of income redistribution to achieve the Pareto-optimal state (for example, the distributive pension plan, etc.). Another source of institutional traps in the society of welfare is the effect of coordination which includes an essential outer effect of following the ineffective norm by a considerable part of society, i.e. the dependence of function of usefulness or production capabilities of the economic agent on a choice of other economic agents.

Following inefficient norms reduces transaction expenses for economic agents. In the conditions of modern Russian economy this phenomenon reveals itself in the opportunistic behavior (one- or bi-lateral opportunism, for example, opportunism of bureaucracy and state services consumers, etc., initiated by the inefficiency of institutes of the budgetary system), in tax offenses and tax crimes stimulated by the informal institutes (public opinion), etc [3].

It determines the preservation of company towns characterized by low diversification of the spheres of employment of the population, considerable dependence of city budget revenue on the activity of one (or several) large enterprises. The cultural inertness manifests itself in stereotypes living a long life, and maintains functioning of inefficient institutes. The similar stereotype of interaction in the system "the state - the population", treated according to the principles of neoinstitutionism as the relation "agent - principal", reveals itself in the tendency of the principal to reduce the volume of compulsory payments and contributions in the structure of consumer expenses at the increase in the volume of received social services which is estimated by the principal as the increase of efficiency level of social contracting.

Thereby, steady orientation of the population to receive the budgetary transfers is formed. It reduces the incentives to conduct business activity and incentives to accumulate and implement human capital.

\section{Results}

The analysis of a considerable number of institutional traps allowed to determine a certain number of inefficient norms in the real sector of Russian economy, the existence of which is caused by the system of the institutional design the target objectives of which are defined according to the key principle of the neoclassical paradigm, i.e. the principle of methodological individualism.

The realization of this principle has led to the formation of the trap of rent-oriented behavior as a stable norm which prevents from the realization of innovatively focused strategy of development of certain economic entities, territorial subdivisions and state in general, interfaced with rather higher volume of transaction expenses; the trap of catching-up development and copying, caused by high transaction expenses of creation of primary and system-based innovations, 
and also by the inefficiency of institutes of protection the intellectual property rights; the trap of preference of income in the short-term period which are conditioned by low degree of stability of formal institutes regulating business activity and of inefficiency of the mechanism of contracts enforcement; a trap of public finance system which arise owing to the complexity of identification of collective preferences of the population, inefficiency of public control institutes and the lack of possibility for collective actions.

The way out of the institutional trap presupposes the necessity of referencing the expenses of cancellation and expenses on its functioning. In case of excess of the latter it seems absolutely necessary to design a new or transformed institute as regards to the effects of coordination, interconnection and cultural inertia, and also as regards to the expenses on adaptation of the new institute to institutional environment and destructions of the mechanism of lobbying of the ineffective norm. The productivity of the institutional design system is defined according to the recognition of the rational choice to increase the welfare of economic agents without restricting their autonomy as a target objective [2].

The analysis of the state regulation measures of Russian economy in general, the industrial complex in particular, and the assessment of results of their implementation applying the methodological approach offered in this work showed that there stay unresolved tasks connected with the transition from resource-oriented to innovation-focused type of development characterized by overcoming the inherent economic structure and by the formation of effective institutes. Thus cognitive and behavioural anomalies initiating the formation of institutional traps serve as the reason of low efficiency of state regulatory control measures towards the economic processes. In this respect it seems necessary to implement the methodical approach based on the principles of new paternalism according to which the state has to implant the normative standard into the structure of subjective preferences of economic agents. The content of this standard is defined by the vector of post-industrial economy development and based on refusal from methodological individualism in favor of the principle of complementarity of individual and social benefits.

The basic parameters of the forecasting scaling factor formed for the assessment of the current state and development prospects of an industrial enterprise [8] in the conditions of new paternalistic economy, which are treated as the initial parameters for three-level perception, are the integral criteria characterizing financial activity of an industrial economic entity, productivity and quality of client relations, efficiency of internal business processes, dynamics of training and organization development with the account of the importance of specific factors defining the trend of the industrial enterprise development in the conditions of the type of economy under research [1] (fig. 1). c

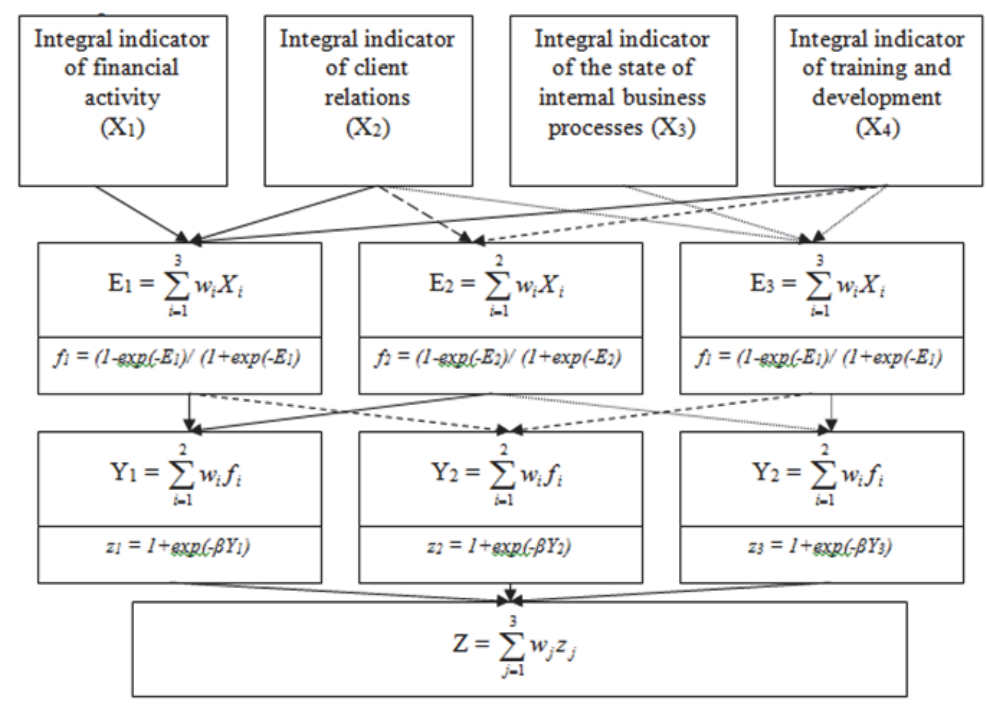

Fig.1. Three-level perception of forming the scaling factor of forecasting the results of industrial enterprise activity in the conditions of new paternalistic economy.

The applied adjusting factor $\beta$ also is defined on the basis of the analysis of the formed tendencies of economic entity development in the industrial sphere. The received indicator $Z$ is the basis for formation of the scaling factor when forecasting the results of activity of the industrial enterprise, and if $Z$ takes on the value smaller than 0,3 , the up-scaling 
factor $1+Z$ is applied; if $Z$ takes on the value from 0,3 to 0,7 , the scaling factor is defined as $1+Z / 3$; in case if $Z$ takes on the value bigger than 0,7 , the scaling factor $(1 / Z-1)$ is applied - that means that one of three types of the factor $K z$ is applied. This scaling factor is used in the multiplicative model of forecasting the results and/or efficiency of activity of an enterprise of the industrial sphere along with the basic value of the predicted $I_{0}$ indicator, the extrapolation coefficient $\mathrm{Ke}$ and the coefficient of dynamics of the macroeconomic scenario realized in new paternalistic economy $\mathrm{Km}$. Thus, the predicted indicator $I_{1}$ can be calculated as follows:

$$
I_{1}=I_{0} K_{z} K_{e} K_{m}
$$

The implementation of inconsistent processes of globalization and regionalization causes autonomism of territorial institutions as a part of national economic area the administrative borders of which do not always coincide with spatial boundaries. And the border of subnational territorial subdivisions is treated as a rupture of the set of contract relations due to the decrease of frequency and intensity of transactions at the movement from the center to the periphery which determines the excess of transaction expenses over transformation ones in case of negotiating contracts with nonresidents of the given territory $[11,15]$.

Regionalization of economic area determines multidirections of preferences and differences in standard treatments of target objectives of development between the federal center, subnational and subregional subdivisions, which complicates the problem of formation of a rational choice model as the standard pattern and, therefore, the elaboration of universal paternalistic strategy. In this respect the formation of qualitatively new forms of integration (clusters, special economic zones, science cities, etc.) realizing institutional projects, determines the overcoming of contradictions between the administrative-territorial and spatial-economic boundaries, creates prerequisites for the expansion of borders of subnational economic areas and the decrease of the level of radical uncertainty of environment.

The carried-out analysis showed that at elimination of overshoots in the initial data determined by the features of functioning and development of certain industrial entities, there is a logarithmic dependence of the share of public benefits provided by the economic entity to contractors, on the revenue of the industrial enterprise (association) [13, 14]. Numerical parameters of this dependence are defined by the features of concrete enterprises and by the distinctive features of the territory where the economic entity is stationed the economic area of which can be characterized as new paternalistic economy.

\section{Conclusions}

Thus, the necessity of the development and implementation of paternalistic strategy of the industrial development according to methodology of behaviouristic economy is determined by cognitive and behavioural anomalies adjusted as a result of state implantation of normative standards into the structure of subjective preferences of economic agents which causes application of measures of the direct influence limiting the opportunities for an individual choice at a high risk level of irrational behavior, and the measures of indirect influence adjusting the individual choice of short-term benefit, interfaced with high expenses in the long-term period. It proves that the inefficiency of applied measures of state regulation is determined by the lack of adaptable mechanisms in the national economic system the formation of which presupposes the necessity of formation of paternalistic strategies with the account to the principles of behavioural economy.

\section{References}

Аверьянов Б.А., Саркин А.В., Багаутдинова Н.Г. Разработка и внедрение стратегии развития предприятий машиностроительного комплекса в условиях современной российской экономики // World Applied Sciences Journal, Volume 25, 2013.

Shaidullin R.N., Ulesov D.V., Shigabieva A.M. and Safiullin L.N. Innovative Infrastructure in Post-Industrial Society/l World Applied Sciences Journal, 27(13), 2013, pp. 180-183.

Ulesov D.V., Murtazina G., Safiullin L.N. and Saipullaev U.A. Special Aspects of Development of Business in the Knowledge-Based Economy //World Applied Sciences Journal, 27(13), 2013, pp. 189-192.

Safiullin, M.R., Elstin, L.A., Shakirova, A.I. (2012). Evaluation of business and economic activity as a short-term forecasting tool. Herald of the Russian Academy of Sciences, 4, 290-294.

David P.A. Clio and the Economics of QWERTY // American Economic Review, 1985, V. 75, № 2.

Kramin M.V., Safiullin L.N., Kramin T.V., Timiryasova A.V. Drivers of economic growth and investment attractiveness of Russian regions. Life Science Journal 2014; 11(6s): 526 - 530.

Glebova I.S., Sadyrtdinov R. and Rodnyansky D. Impact Analysis of Investment Attractiveness of the Republic of Tatarstan on Fixed Investments of its Leading Companies // World Applied Sciences Journal 26 (7): 911-916, 2013. 
Fakhrutdinova, E., Safina, L., Shigapova, D., Yagudin, R. Legislative provision of the quality of working life in Russia// World Applied Sciences Journal.Volume 27, Issue 13, 2013, Pages 92-96.

David P.A. Understanding the Economics of QWERTY: The Necessity of History // Economic History and the Modern Economist. Ed. by William N. Parker. New York: Basil Blackwell, 1986.

Loewenstein G., Haisley E. The Economist as Therapist: Methodological Ramifications of 'Light' Paternalism // Td. by Caplin A., Schotter A. Perspectives on the Future of Economics: Positive and Normative Foundations. The Handbook of Economic Methodologies. Vol. 1. Oxford: Oxford University Press. 2006.

Kirshin I.A., Datsyk A.A., Titov A.V. Forecasting the Dynamics of an Innovative Cycle. - World Applied Sciences Journal (Economics, Management and Finance). - 2013. - №27. - P. 197 - 201.

Safiullin L.N., Gafurov I.R., Shaidullin R.N., Safiullin N.Z. Socio-economic development of the region and its historical and cultural heritage. Life Science Journal 2014; 11(6s): 400-404.

Mitchell G. Libertarian Paternalism Is an Oxymoron // Northwestern University Law Review. 2005. Vol. 99. No. 3. P. $1245-1277$.

Rizzo M. J., Whitman D. G. The Knowledge Problem of the New Paternalism // Brigham Young University Law Review. 2009. No. 4. P. 905-968.

Sugden R. Why Incoherent Preferences Do Not Justify Paternalism // Constitutional Political Economy. 2008. Vol. 19. No. 3. P. $226-248$. 
